January 2018

\title{
Challenges to Disciplinary Knowing and Identity: Experiences of Scholars in a SoTL Development Program
}

Janice E. Miller-Young Dr

University of Alberta, jmilleryoung@ualberta.ca

Michelle Yeo

Mount Royal University, myeo@mtroyal.ca

Karen Manarin

Mount Royal University, kmanarin@mtroyal.ca

Follow this and additional works at: https://digitalcommons.georgiasouthern.edu/ij-sotl

\section{Recommended Citation}

Miller-Young, Janice E. Dr; Yeo, Michelle; and Manarin, Karen (2018) "Challenges to Disciplinary Knowing and Identity: Experiences of Scholars in a SoTL Development Program," International Journal for the Scholarship of Teaching and Learning: Vol. 12: No. 1, Article 3.

Available at: https://doi.org/10.20429/ijsotl.2018.120103 


\title{
Challenges to Disciplinary Knowing and Identity: Experiences of Scholars in a SoTL Development Program
}

\author{
Abstract \\ Faculty members from five years of an annual Scholarship of Teaching and Learning (SoTL) development \\ program were invited to participate in a study about the impact of SoTL on their teaching, scholarship, \\ and career trajectory. During semi-structured interviews, many expressed feeling discomfort during their \\ journey into SoTL. A qualitative analysis using the constant comparison method showed that this \\ discomfort was sometimes due to contrasts between SoTL and their discipline's epistemology, as well as \\ challenges to their identity as a teacher, researcher, and a colleague. We conclude with suggestions for \\ how faculty development and multidisciplinary SoTL communities of practice can be planned and \\ managed.

\section{Keywords} \\ faculty development, multidisciplinary, SoTL, discomfort, epistemology, identity

\section{Creative Commons License} \\ c) (i) $९$ \\ This work is licensed under a Creative Commons Attribution-Noncommercial-No Derivative Works 4.0 \\ License.

\section{Cover Page Footnote} \\ We would like to thank the Institute for Scholarship of Teaching and Learning at Mount Royal University \\ for the financial support of this research, and our colleagues for their honesty and willingness to \\ participate in this study.
}


IJ-SoTL, Vol. 12 [2018], No. 1, Art. 3

\title{
Challenges to Disciplinary Knowing and Identity: Experiences of Scholars in a SoTL Development Program
}

\author{
Dr. Janice E. Miller-Young', Michelle Yeo², Karen Manarin ${ }^{3}$ \\ 'Centre for Teaching and Learning, University of Alberta, Edmonton, Alberta T6G 2J8, Canada \\ ${ }^{2}$ Academic Development Centre, Mount Royal University, Calgary, Alberta T3E 6K6, Canada \\ ${ }^{3}$ Department of English, Mount Royal University, Calgary, Alberta T3E 6K6, Canada
}

(Received 20 March 2017;Accepted 10 July 2017)

Faculty members from five years of an annual Scholarship of Teaching and Learning (SoTL) development program were invited to participate in a study about the impact of SoTL on their teaching, scholarship, and career trajectory. During semi-structured interviews, many expressed feeling discomfort during their journey into SoTL. A qualitative analysis using the constant comparison method showed that this discomfort was sometimes due to contrasts between SoTL and their discipline's epistemology, as well as challenges to their identity as a teacher, researcher, and a colleague. We conclude with suggestions for how faculty development and multidisciplinary SoTL communities of practice can be planned and managed.

\section{INTRODUCTION}

Engaging in the Scholarship of Teaching and Learning requires instructors to critically reflect on aspects of their practice, examine their beliefs about teaching, consider their sense of self in relation to their practice, and even question and challenge institutional and social norms related to teaching (Cranton 20I I; Kreber 2013; Manarin and Abrahamson, 2016). Engaging in such work can be challenging, particularly for those who are not experienced in learning-related inquiry. While a substantial body of literature has highlighted many factors that impede change such as lack of training, time, and incentives (e.g. Boshier 2009; Kelly, Nesbit, \& Oliver, 2012), other barriers, which tend to be less visible, are beginning to receive attention. These include epistemological barriers and tensions between academic identities (Simmons et al., 20I3; Marquis et al., in press). Understanding the factors and contexts which cause such challenges is important for those who practice SoTL as well as those who aim support it.

The Nexen SoTL Scholars Program at a Canadian undergraduate, teaching-focused university was designed to support an annual cohort of instructors to develop individual SoTL research projects to be conducted in their own course.The detailed structure of the program has been described elsewhere (Miller-Young et al. 20I6). In short, over the course of a year, participants from different disciplines and with varying degrees of research experience work within a facilitated learning community to move from refining a SoTL research question through design, data gathering, and the beginning of data analysis. Participants were also required to give feedback during the design and conduct of their peers' projects. The learning community was facilitated by academic developers as well as alumni of the program; two of the authors were participants of this program and subsequently became facilitators of the program, the other author was also a facilitator. After the program had run for five years, all participants were invited to participate in a survey and follow-up interviews inquiring into the influence of the program on these scholars' teaching, scholarship, and career trajectories. These participants reported impact at an individual, departmental, institutional, and disciplinary level (Miller-Young et al. 20 I6). Many participants also described feeling discomfort during their journey into SoTL. The most frequent reason seemed to be a tension between SoTL and their academic discipline, which often led to a questioning or shifting in identity. It is the variety of ways these tensions and shifts occurred which we explore in this paper.

\section{Learning, Discomfort, and SoTL}

Discomfort has long been acknowledged as part of the learning process. From a cognitive perspective, Piaget (1975) posited a state of disequilibrium in children when new information cannot fit into existing schemas; as Adcock (20I2) notes, "this dissonance is seen as an essential trigger for the learning process" (p. 588). Mezirow's (1978) theory of transformative learning in adult education begins with the "disorienting dilemma" and leads to re-examination of perspectives and relationships through rational reflection. Similarly, according to the Thresholds Concepts framework (Meyer and Land 2003, 2005; Meyer 2008) learning a threshold concept resembles passing through a portal, towards a transformed understanding. The experience of being in the liminal space, where one struggles to negotiate new meanings, can be troublesome. Perkins (1999) identified some knowledge as "troublesome" for learners when it is counter-intuitive, alien, or perceived as incoherent; he later went on to identify some epistemes as potentially troublesome (Perkins 2012). Exposure to new ways of knowing that challenge assumptions can be particularly troublesome.

Whenever faculty engage in multidisciplinary and interdisciplinary spaces or work, they are required to not only to learn new vocabulary, but also to increase their understanding of different conceptions of knowledge and methods of inquiry (Lattuca and Creamer, 2005). This can pose a considerable challenge to their epistemological beliefs, or ways of conceptualizing the nature of knowledge, as well as their professional identities (Irvine and Carmichael, 2009; Lattuca, 2005; Meyer and Land, 2005). Such troublesome and disorienting encounters can take place both when a faculty member engages in a learning community with colleagues from other disciplines (Cox 2004; Strober 20I I) and also when they must learn new ways of conducting research in order to engage in SoTL.

For the purposes of this article and the program being studied, SoTL was defined as the practice of inquiring into student learning in higher education. We are guided by the words of Potter and Kustra (20II), who described SoTL as:

the systematic study of teaching and learning, using established or validated criteria of scholarship, to understand 
how teaching (beliefs, behaviours, attitudes, and values) can maximize learning, and/or develop a more accurate understanding of learning, resulting in products that are publicly shared for critique and use by an appropriate community. (p. 2)

This definition is inclusive of the wide range of methods and philosophies (Miller-Young and Yeo 20I5; Divan et al. 2017) used in SoTL. Not surprisingly, faculty from more positivist disciplines such as science and engineering often experience barriers and discomfort when engaging in SoTL. Some studies of STEM instructors have focused on the epistemological shifts required, such as learning to appreciate qualitative and mixed methods approaches to research (Borrego 2007; Kelly et al. 20I2). To our knowledge, little research has been done on whether SoTL practitioners from social science disciplines experience epistemological discomfort, perhaps because of assumptions that SoTL is a social science. Indeed, in a study of the threshold concepts experienced by faculty in a SoTL development program, some of which were epistemological in nature, Webb (2016) explicitly describes SoTL as a social science. However, humanities scholars have also shared experiences of discomfort and marginalization due such expressions in the majority of SoTL discourse that imply SoTL is empirical, objective research, and have argued for the benefits of humanities approaches to SoTL (Bloch-Schulman et al. 2016; Chick 2013; Potter and Wuetherick 2015). Further, SoTL's lack of a single epistemological stance nor consensus about validity of findings or contributions, can also cause anxiety for scholars new to the field (Fanghanel et al., 2016; MacKenzie et al., 2010). In summary, scholars from most disciplines do seem to experience some transformation and associated discomfort when engaging in SoTL.

While the process of how scholars learn to do SoTL research is one aspect of study, studying what constitutes their professional identity is another. Identity can be thought of as how a person thinks of themselves in a particular context, which can change with time and is continuously modified based on the surrounding environment (Mead 1934). In academia, professional identities are shaped by our disciplines and are primarily research identities rather than teaching identities (Austin 2002; Henkel, 2005; Kreber 2010). Thus, engaging in a multidisciplinary endeavour such as SoTL can create anxiety for some academics, who may fear a loss of disciplinary identity and/or status, or may fear giving up their expert-ness (Huber 2005; Tremonte $20 \mathrm{II}$ ). Despite an awareness of this difficulty in the literature broadly, difficulties with conflicting identities continue to appear in studies related to faculty engaging in SoTL research. Recently, in an analysis of the identity trajectories of engineering education researchers, Gardner and Willey (2016) found that emerging researchers were very concerned about their research being less valued than technical research by their peers. Indeed, Brownell and Tanner (2016) suggest that the research-centric professional identity which exists in the STEM fields is the primary barrier to participating in pedagogical change. A study of the identity development of a multidisciplinary group of SoTL scholars found common themes of doubt and insecurity about learning to do SoTL, reconfiguring and assimilation of conflicting identities over time, and the importance of engaging in a SoTL community for support (Simmons et al.2013). Similarly, in a group autoethnography of research fellows transitioning from a variety of disciplines to becoming SoTL scholars, participants initially expressed a re- luctance to identify as SoTL scholars, which diminished as they gained knowledge and understanding of SoTL over time (Marquis et al, in press). Understanding the nature of SoTL scholar identity development in a variety of contexts will help in supporting others' transformation from disciplinary academic to SoTL researcher.

An area that remains relatively unexplored is examination of the epistemological tensions and disruptions in identity which arise for faculty members when they engage in a multidisciplinary community of practice designed to support their SoTL. Marquis et al. (in press) and Webb (2016) are two exceptions; however, both these studies took place at research intensive universities and we find different dynamics at play in our own teaching focused context. Further, our study includes scholars from a greater diversity of disciplines and professional programs including education. Specifically, this study addresses the variation in epistemological difficulties experienced by participants from different disciplines and the multiple ways their identities were challenged.

\section{METHODOLOGY}

All scholars who participated in the first five years of the SoTL Scholars program at Mount Royal University were invited to participate in this focused ethnography (Knoblauch 2005). According to this methodology, when the researchers have a close familiarity with the members of the community under investigation, data collection can occur in short, intense phases (Higginbottom, Pillay, and Boadu 2013). Thus, data collection consisted of semi-structured interviews about the impact of the program and their SoTL project on their teaching, research, and career trajectory. Seventeen scholars participated in interviews from disciplines as wide-ranging as English and chemistry, as well as from professional programs such as nursing and education. One researcher from the team conducted all but one interview, and the entire research team met regularly over the period of the interviews to discuss emerging themes. This ensured consistency of interview protocol and allowed us to determine as a team when we had reached saturation in that no new themes were emerging from the interviews. Interviews were audio-recorded and transcribed.

After a preliminary thematic analysis conducted by all members of the research team, we identified a number of sources of discomfort mentioned in the interviews. The two most frequently mentioned sources of discomfort were a tension between SoTL and the participants' discipline, and discomfort with the definition of SoTL itself. These tensions existed for participants whose disciplines were both cognate with SoTL (e.g. education) as well as distant, and seemed to result in a questioning or shifting of identity. We then chose to re-analyze the data looking for evidence of discomfort specifically related to epistemology and identity. One researcher examined the interviews using the constant comparison method (Glaser and Strauss, 1967) to identify quotes and find themes related to these types of discomfort. Clear themes emerged in this analysis, and results were discussed with the entire research team until consensus was reached. 


\section{FINDINGS}

Participants experienced (a) discomfort due to contrasts between SoTL and their discipline's epistemology, and (b) discomfort due to disruptions in identity, specifically changing understanding of themselves as a teacher, researcher, and a colleague. Quotes from the interviews are presented, below, to illustrate.

\section{Epistemological Discomfort}

It was clearly evident in the interviews that disciplinary epistemology was a source of discomfort for participants. While scholars from STEM disciplines were uncomfortable with the perceived subjectivity of SoTL, humanities scholars noted a lack of reflexivity. Scholars from cognate disciplines like education were uncomfortable with the interdisciplinary nature of SoTL.

Discomfort with Subjectivity. STEM participants described a discomfort related to the perceived subjectivity of SoTL. One scholar's comments focused on the nature of certain kinds of data which is often collected in SoTL studies, such as self-reported learning and reflections. Their quote, below, also illustrates an initial discomfort with not being an "objective" researcher who is external to the context being studied:

Initially I wasn't comfortable with the idea of any subjectivity at all. I didn't want reflections, I didn't want student opinions... Now I understand that depending on the type of (research) question it is okay to be subjective because you are part of the teaching and learning process - you are half of the equation.

This quote also demonstrates how the participant later became aware of different types of research questions (and thus, epistemologies), and, although they only used language from their own discipline ("equation"), they expressed an awareness of reflexivity in some types of research. In other words, they seemed to become more comfortable with SoTL research as a more bidirectional relationship in which both the researcher and the researched can affect one another. Initial discomfort with the size of a study, in terms of number of participants, was also expressed by STEM scholars, and is illustrated in this quote from a different participant:

I was reading a lot of one-person case studies and thought, this just goes against everything I can think of? It really made me question the validity of SoTL... then I started realizing that the literature is so vast that there are various approaches to look at different questions, and I think that helped.

The above quote also expresses a new awareness of, and apparent openness to, different approaches to research and a variety of types of research questions.

Discomfort with Objectivity. While faculty members from the Humanities were aware of a broader spectrum of research approaches and questions, they expressed discomfort with language and perspectives which positioned SoTL in an empirical realm, in other words, that SoTL had the underlying assumption that research attempts to study an observable reality, and is as objective as possible in its approach. As one participant expressed,

I was a little put off by some of the language... like "data," you know, students as "data"; "qualitative methodology" ... even "methodologies"... That is not my realm, that is not my domain. I don't see how I am going to be able to fit here ... the sense of "empirical, evidence-based" it somehow made me run, or think that how could I potentially offer something to that? ... Now I am trying to theorize and get at some of what I see is absent, which is self-reflexivity in SoTL.

Another participant also expressed discomfort with underlying methodological and theoretical assumptions of SoTL, as well the sometimes uncritical approach to analyzing student learning that she observed:

sometimes SoTL work reads student texts too literally, like too unproblematically, because words always lie in one way or another, so just because someone says something doesn't make it true even if they believe it is true at that particular moment ... Thinking in various theoretical frames, what else might be there that is not quite on the surface? I think that a lot of SoTL work is still primarily using a psychological frame and I don't know that that is the most helpful frame for student learning; even if we could get to the sociological frame I think we would have a better representation.

So both STEM and Humanities participants felt uncomfortable with the epistemological clash between SoTL and the home discipline though in opposite directions: SoTL was simultaneously too subjective and too objective in a multi-disciplinary group.

Discomfort with Interdisciplinarity. SoTL is a field that strives to be interdisciplinary and even transdisciplinary (Poole 2013 ) in that the field of knowledge integrates or transcends the contributions that can be made from any one discipline. However, participants from cognate fields such as education often expressed an annoyance at SoTL's definitional debates and a perception that SoTL is anything new or different from what they were already doing. One participant illustrated an awareness of SoTL as a different space but an unwillingness to engage in that space:

I think if I had to stay with the SoTL literature it would have really reduced my ability to make sense of this ... I am less willing to go into SoTL and give up what I have learned here.

Part of this unwillingness was related to the time and effort it would take to conduct a review in another body of literature, but they also didn't seem to think there was anything to be gained by doing so. The same participant described how, after it was suggested to them that they present their work at a SoTL conference, they had difficulty in seeing what they might contribute. They did go on to present and described how this helped them realize that their work transcended disciplines:

I was concerned because I thought "What do we really have to say?" so that in itself might be another little shift to say we actually have something bigger than teacher ed, maybe this could apply to people not in education.

This quote illustrates a new awareness of the potential benefit of communicating across disciplines, although they only articulated the benefit to other disciplines, not their own. Also evident was some members' discomfort that their expertise was not taken up:

When you don't feel your voice is being heard in terms of shaping what the definition of SoTL is here you have got a couple of choices, the old fight or flight. I will be honest, I just took a bit of a flight.... I don't feel like anybody cares about me contributing!

While participants from STEM and Humanities disciplines struggled to adapt to new epistemologies, participants from cognate disciplines struggled to see SoTL as distinct from what they al- 
ready knew/did. They did not want to see themselves as novices, which leads to our next category.

\section{Discomfort due to disrupted Identity}

Engaging in the SoTL scholars program caused participants to consider their sense of self related to three themes: Who am I as a teacher? Who am I as a researcher? Who am I with my colleagues?

Self as teacher. Many of our participants described how they joined the program primarily to learn a new type of research, and expressed surprised that engaging in SoTL actually changed their teaching. They also expressed discomfort not only because of a new understanding that their previous pedagogical approaches had not always been ideal, but also because they were holding themselves to a new, higher standard. One participant's words illustrate this particularly well:

I think I am a better teacher now, I think my students are learning more, but we are all working harder and they are more uncomfortable and sometimes I am uncomfortable ... if anything I am just more unsure of my teaching now than I ever was.

For this participant, the discomfort triggered by the program has not eased, but the discomfort is seen as productive.

Self as researcher. As was described by Webb (2016), feelings of discomfort were often associated with a sense of lack of expertise in a new research approach, or in the case of the cognate disciplines, the idea that they might lack expertise. Some participants expressed discomfort at not being an expert at SoTL research, but seemed to embrace learning something new and even derive energy from it. This openness to learning was reflected in the following comment:

I am completely out of my comfort zone a huge amount, which makes it more exciting in some ways, and a little bit of grieving to let go of what I know... If this hadn't gone well I would say "Great, chalk that up to a year's experience" and get back into my own stuff.

However, one participant described the experience as being uncomfortable enough to make her give up and return to solely doing disciplinary work:

I realized after the fact that I didn't actually collect the right data to answer my questions so I just thought it was a mess and there was nothing there. I think at that point I was very disillusioned. I felt "I have always been good at disciplinary research and I didn't do this so well so maybe I shouldn't go this way."... When I went back and did some of the work in my discipline I went, "Phew! This is so much less stressful!"

Another participant seemed to enjoy the learning and wanted to further develop their SoTL research expertise, but expressed frustration at the constraints of their teaching context, where they often did not teach the same courses from year to year, which prevented them from both developing a research trajectory and acting or building on their findings:

So I guess I am just pursuing studies that seem to fit in the courses that I happen to be teaching ... and that is a strain I don't think I can continue much longer, to be honest. ... it is causing me dissatisfaction ... I think there are two strands to the frustration, and one is that I am always doing something new so I don't feel that I am developing any deep expertise in any one particular area, and the other is that there is not a lot of room for experimenting with implementation [of what I have learned].

Finally, for one humanities scholar there was also a tension between a sense of academic identity as an independent scholar and the expectation to participate within a learning community:

it felt like you were going in and getting indoctrinated and then come out! So I was little leery of that ... I think the autonomy that I treasure and perhaps take for granted as an academic, I was pricking a bit at being part of a group ...I was concerned with group-think.

Unlike many STEM and social science researchers, humanities scholars are often trained to work alone; working within a larger group, even on an independent project, can be challenging. A significant aspect of identity is a sense of competence, expertise, or ability. These comments illustrate how discomfort as a researcher was associated with not just being a novice in a new field, but lack of control over one's research context as well as, for at least one humanities scholar, being expected to join a multidisciplinary community.

Self as member of disciplinary community. It was clear that participating in the SoTL multi-disciplinary learning community changed how participants saw themselves in relation to their colleagues in their department and discipline.

After being immersed in this academic community I found it really difficult to reintegrate back into my department, and there was sort of a frustration on my part that they weren't engaged in these things that I thought were clearly worthy of everybody being engaged in.

While this quote indicates an interest in engaging departmental colleagues in SoTL, others expressed that they were still in a liminal space and felt a lack of readiness to share with their colleagues what they had learned. One STEM participated illustrated this by saying,

I didn't feel confident enough to go back to my science colleagues and say "Okay, this is what qualitative research is about and this is why it is just as valuable as scientific research." I didn't have the language. I hadn't spent enough time with the ideas. I don't know if I even really believed it yet myself ... I quietly went about my own business for quite $a$ while before I was ready to talk about it with my science colleagues.

These participants' comments show their shifting identity in relation to how they engage with their colleagues.

\section{DISCUSSION}

The SoTL movement has focused on engaging faculty across disciplinary boundaries however the difficulties this can generate should not be underestimated. This analysis explores the multiple sources of discomfort experienced by faculty members as they engaged in a multidisciplinary community of practice designed to support them in developing a course-based SoTL research project. Epistemology was a source of discomfort for participants from STEM and the humanities, for opposite reasons, while scholars from cognate disciplines like education were uncomfortable with the interdisciplinary nature of SoTL. Participants also experienced a disruption in their sense of identity, causing them to question themselves as a teacher, researcher and colleague. 
It is perhaps not surprising that epistemology can be a source of discomfort. While other studies have addressed this issue for STEM and humanities scholars, our findings also demonstrate 'discomfort' in cognate fields such as education. More specifically, we suggest that the epistemological discomfort arises from a change in how the researcher is positioned in relation to the data and the participants. If you are trained to be an outside observer, the subjectivity and proximity of SoTL research is uncomfortable. For humanities scholars the relationship between SoTL researcher and the research is not reflexive, or critical, enough. For cognate disciplines, the discomfort stems from letting go of their position of "already expert." Finally, participants from all disciplines express their struggle with and desire to influence and bring something to the field of SoTL.

Disciplinary affiliation plays a central role in academics' sense of identity however identity is constantly shifting. Colley and James (2007) understand professional and academic identities as 'disrupted processes' that involve not only 'becoming' but also 'unbecoming'. The troublesomeness of our participants' identity reconstruction was evident through their disrupted sense of competence and ability as a teacher, researcher, and disciplinary colleague. These findings align with those of Bennett et al. (2016); however, their participants were scholars who worked in a centralised academic skills support centre. For our participants, who came from diverse faculties across our institution, their discomfort sometimes had serious consequences; while some seemed to see it as productive and exciting, others described how it caused them to retreat from SoTL. Evident in others' comments was the need for more time to engage with new ideas and to develop a sense of confidence. It would be interesting to follow up with those who have continued to engage in SoTL, to examine whether they are also experiencing an 'unbecoming' as a disciplinary scholar.

This study has important implications for how faculty development and SoTL communities of practice are planned and managed. We acknowledge the benefits that result from the 'disorienting dilemma' of encountering new conceptions of knowledge and approaches to research; however, the potential discomfort due to this disruption must be attended to. Our program was designed such that participants entered the cohort with their own SoTL research question in mind (Bass 1999), and no time was spent explicitly exploring or bridging disciplinary differences. Strober's (20II) recommendations for leading interdisciplinary conversations are particularly helpful in considering ways we could have done so. According to Strober, providing both structure and ample space to explore disciplinary differences requires a leader with sufficient authority (either through position and/ or experience), who creates productive conflict (by facilitating but also mediating in-depth discussions), and who bridges disciplinary cultures (by being able to compare and contrast the strengths and limitations of different disciplinary ways of knowing, including their own).

Due to the complexity and variety of our participants' experiences, and considering our findings in relation to Strober's recommendations, we have a number of specific recommendations for facilitating multidisciplinary SoTL development programs. First, we have developed and suggest integrating resources which explicitly describe the range of methodologies and theoretical perspectives on learning which can be used in SoTL and across disciplines (e.g. Miller-Young and Yeo 20I5). Second, we believe it is important to acknowledge the potential for discomfort upfront and to prepare researchers for it, for example through sharing stories of the experiences of others. Third, it is important to attend to group relations, develop an atmosphere of trust and openness, and create a sense of belonging for each individual in the group by attending to those feeling uncomfortable, by encouraging participants to suspend judgement of new ideas and methods, and by communicating that the diversity of disciplines and expertise is a strength. Finally, facilitators should be aware of these different types of discomfort in order to be able to recognize and respond to them when they occur. In addition to allowing sufficient time and space for new researchers to move through their learning process, we are also providing other structured interventions and supports where disciplinary expertise is shared, such as regular discussions of published studies which use a variety of epistemologies and methodologies through a journal club.

We believe that a multidisciplinary community of practice can not only provide professional development for faculty members as both teachers as researchers, but also will provide a community and foster the exchange of ideas across an institution, thus contributing to innovation and improvement in teaching and learning. We hope that sharing our colleagues' experiences will help other facilitators and scholars in resolving their own SoTL development challenges. Being mindful of the types of discomfort faculty members may experience through such an initiative will support engagement with SoTL as a worthwhile intellectual and personal journey.

\section{Acknowledgements}

We would like to thank the Institute for Scholarship of Teaching and Learning at Mount Royal University for the financial support of this research, and our colleagues for their honesty and willingness to participate in the study.

\section{REFERENCES}

Adcock, A. (20I2). Cognitive dissonance in the learning process. Encyclopedia of the science of learning, 588-590.

Austin, A. (2002). Preparing the next generation of faculty: graduate education as socialization to the academic career. Journal of Higher Education 73, 94-I 22.

Bass, R. (1999) The Scholarship of teaching:What's the problem? Inventio: Creative Thinking about Learning and Teaching, I(I).

Bennett, R., Hobson, J., Jones, A., Martin-Lynch, P., Scutt, C., Strehlow, K., \& Veitch, S. (20I6). Being Chimaera: A monstrous identity for SoTL academics. Higher Education Research \& Development, 35(2), 217-228.

Bloch-Schulman, S., Conkling, S. W., Linkon, S. L., Manarin, K., \& Perkins, K. (2016). Asking Bigger Questions:An Invitation to Further Conversation. Teaching \& Learning Inquiry, 4( I), I-7.

Borrego, M. (2007). Conceptual difficulties experienced by trained engineers learning educational research methods. Journal of Engineering Education, 96(2), 91.

Boshier, R. (2009).Why is the scholarship of teaching and learning such a hard sell? Higher Education Research and Development, 28(I), I- I5.

Brownell, S. E., \& Tanner, K. D. (20I2). Barriers to faculty pedagogical change: lack of training, time, incentives, and... tensions with professional identity? CBE-Life Sciences Education, I I (4), 
339-346.

Chick, N. L. (20I3). Difference, privilege, and power in the scholarship of teaching and learning: The value of humanities SoTL. The scholarship of teaching and learning in and across the disciplines, 15-33.

Colley, H., James, D., \& Diment, K. (2007). Unbecoming teachers: Towards a more dynamic notion of professional participation. Journal of Education Policy, 22(2), I73-193.

Cox, M. D. (2004). Introduction to faculty learning communities. New directions for teaching and learning, 2004(97), 5-23.

Cranton, P. (20II). A transformative perspective on the scholarship of teaching and learning. Higher Education Research \& Development, 30(I), 75-86.

Divan, A., Ludwig, L., Matthews, K., Motley, P., \& Tomljenovic-Berube, A. (2017). Survey of research approaches utilised in the scholarship of teaching and learning publications. Teaching \& Learning Inquiry, 5(2), 16-29.

Fanghanel, J., McGowan, S., Parker, P., McConnell, C., Potter, J, Locke, W., \& Healey, M. (20I6). Literature review. Defining and supporting the scholarship of teaching and learning (SoTL): a sector-wide study. York: Higher Education Academy.

Gardner,A., \&Willey, K. (20I6).Academic identity reconstruction: the transition of engineering academics to engineering education researchers. Studies in Higher Education, I- 17.

Glaser, B., \& Strauss, A. (1967). The discovery of grounded theory. Chicago:Aldine.

Henkel, M. (2005).Academic identity and autonomy in a changing policy environment. Higher Education, 49( I-2), I 55- I 76.

Higginbottom, G., Pillay, J., \& Boadu, N. (20I3). Guidance on performing focused ethnographies with an emphasis on healthcare research. The Qualitative Report, 18(17): I- 16.

Huber, M.T. (2005). Balancing acts:The scholarship of teaching and learning in academic careers. Sterling,VA: Stylus.

Irvine, N. \& Carmichael, P. (2009). Threshold concepts: A point of focus for practitioner research. Active Learning in Higher Education, 10(2), 103-119.

Kelly, N., Nesbit, S., \& Oliver, C. (20I2). A difficult journey: Transitioning from STEM to SOTL. International Journal for the Scholarship of Teaching and Learning, 6(I).

Knoblauch, H. (2005). Focused ethnography. Forum qualitative sozialforschung/forum: qualitative social research 6(3).

Kreber, C. (20I0). Academics' teacher identities, authenticity and pedagogy. Studies in Higher Education, 35(2), I7I- 194.

Kreber, C. (20I3). Authenticity in and through teaching in higher education:The transformative potential of the scholarship of teaching. Routledge.

Lattuca, L. R. (2005). Faculty work as learning: Insights from theories of cognition. New Directions for Teaching and Learning, 2005(I02), I3-2I.

Lattuca, L.R., \& Creamer, E.G. (2005). Learning as professional practice. New Directions for Teaching and Learning, 2005( 102 ), 3-II.

MacKenzie, J., Bell, S., Bohan, J., Brown, A., Burke, J., Cogdell, B., ... Paschke, B. (2010). From anxiety to empowerment: a learning community of university teachers. Teaching in Higher Education, 15(3), 273-284.

Manarin, K., \& Abrahamson, E. (2016). Troublesome knowledge of SoTL. International Journal for the Scholarship of Teaching and Learning, 10(2), 2.

Marquis, E., Holmes, T., Apostolou, K., Centea, D., Cockroft, R.,
Knorr, K., ... Karamanis, T. (in press). SoTL research fellows: Collaborative pathfinding through uncertain terrain. Canadian Journal for the Scholarship of Teaching and Learning.

Mead, G.H. (1934). Mind, self and society. Chicago: University of Chicago Press.

Meyer, J.H.F., \& Land, R. (2003) Threshold concepts and troublesome knowledge: Linkages to ways of thinking and practising, In: Rust, C. (ed.), Improving student learning: Theory and practice ten years on. Oxford: Oxford Centre for Staff and Learning Development.

Meyer, J.H.F., \& Land, R. (2005) Threshold concepts and troublesome knowledge (2): Epistemological considerations and a conceptual framework for teaching and learning, Higher Education, 49(3), 373-388.

Meyer, J. H. (2008). Threshold concepts within the disciplines. Sense Publishers.

Mezirow, J. (1978). Education for perspective transformation:Women's re-entry programs in community colleges. New York:Teacher's College, Columbia University

Miller-Young, J., \& Yeo, M. (20I5). Conceptualizing and communicating SoTL:A framework for the field. Teaching and Learning Inquiry, the ISSoTL Journal, 3(2), 37-53.

Miller-Young, J., Yeo, M., Manarin, K., Carey, M., \& Zimmer, J. (20I6). SoTL2: Inquiring into the impact of inquiry. New Directions for Teaching and Learning, 2016, 55-62.

Perkins, D. (1999). The many faces of constructivism. Educational Leadership, 57(3), 6-II.

Perkins, D. (20/2). Constructivism and troublesome knowledge. In J. H. F. Meyer, \& R. Land (eds.), Overcoming barriers to student understanding:Threshold concepts and troublesome knowledge. (pp. 33-47). New York, NY: Routledge.

Piaget, J. ( 1975). The equilibrium of cognitive structure. Chicago, IL: University of Chicago Press.

Poole, G. (20I3). Square one: What is research? The scholarship of teaching and learning in and across the disciplines, I35-I5I.

Potter, M.K., \& Kustra, E.D.H. (20I I). The relationship between scholarly teaching and SoTL: Models, distinctions, and clarifications. International Journal for the Scholarship of Teaching and Learning, 5(I), Article 23.

Potter, M. K., \& Wuetherick, B. (20I5).Who is represented in the teaching commons?: SoTL through the lenses of the arts and humanities. The Canadian Journal for the Scholarship of Teaching and Learning, 6(2), 2.

Simmons, N., Abrahamson, E., Deshler, J.M., Kensington-Miller, B., Manarin, K., Morón-García, S., Oliver, C., \& Renc-Roe, J. (20I3) Conflicts and configurations in a liminal space: SoTL scholars' identity development. Teaching and Learning Inquiry, I (2), 9-2I.

Strober, M.H. (20I I). Interdisciplinary conversations: Challenging habits of thought. Stanford, CA: Stanford University Press.

Tremonte, Colleen M. (20II). Window shopping: Fashioning a scholarship of interdisciplinary teaching and learning. International Journal for the Scholarship of Teaching and Learning, 5(I), Article 26.

Webb A.S. (2016) Threshold concepts and the scholarship of teaching and learning. In: Land R., Meyer J.H.F., Flanagan M.T. (eds) Threshold concepts in practice: Educational futures (Rethinking Theory and Practice). SensePublishers, Rotterdam. 